\title{
Cardiac Effects of Growth Hormone in Physiology and in Heart Failure
}

\author{
Luigi SACCÀ, SERAfino FAZIO, SALVATORE LONGOBARDI ANd ANTONIO CITTADINI
}

From the Department of Internal Medicine, Federico II University Medical School, Naples, Italy

GROWTH hormone is secreted by the pituitary gland and acts through its tissue effector insulinlike growth factor I (IGF-I). Contrary to the initial hypothesis that IGF-I production takes place only in the liver [1], it is now clear that under the growth hormone stimulus IGF-I may be synthesized in any tissue including the myocardium [2]. In fact, whenever the activity of growth hormone is altered, this is followed by parallel changes in the myocardial IGF-I expression and content. This occurs because the growth hormone receptor is actively expressed in the myocardium, and to a greater extent than in other target tissues [3].

Growth hormone may exert both direct and indirect effects on the heart. The direct effects are essentially two. The first of them consists of the ability of growth hormone to activate cardiac tissue growth with consequent reshaping of ventricular geometry. The second effect relates to the ability of growth hormone to improve ventricular performance, independent of myocardial growth. The suggestion has also been made that growth hormone may improve myocardial energetics and mechanical efficiency. The data regarding this aspect are less solid and this area needs further investigation.

\section{Growth Hormone's Direct Cardiac Effects}

There is direct evidence that IGF-I affects cardiac

Correspondence to: Dr. Luigi SACCÀ, Department of Internal Medicine, University Federico II, Via S. Pansini, 5 80131 Naples, Italy. E-mail: sacca@unina.it

Key words: Growth hormone, Insulin-like growth factor-I, Heart, Cardiac failure cell growth. In cultured cardiomyocytes, IGF-I stimulates protein synthesis and cardiac cell size [4]; in contrast, if the expression of IGF-I is blocked, protein synthesis and DNA replication are blocked. There is extensive animal data supporting a role of the growth hormone/IGF-I axis in the control of cardiac cell growth. Growth hormone secreting tumors activate cardiac growth in parallel to body growth [5]. Furthermore, when administered exogenously in high doses to normal rats, growth hormone and/or IGF-I evoke a hypertrophic response that has been documented both echocardiographically and histologically [6, 7]. In addition to animal data, there is convincing evidence that growth hormone regulates cardiac development and hypertrophy in humans. Most of the human data come from cross-sectional assessment of cardiac morphology in clinical states of altered growth hormone secretion, that is acromegaly and growth hormone deficiency (GHD). We studied a number of acromegalic patients, free of those abnormalities that usually complicate the disease, such as diabetes mellitus, hypertension, and coronary artery disease [8-10]. On the other side, we studied patients with childhood-onset growth hormone deficiency [11-13]. In these patients, the lack of growth hormone during the developmental period has a more serious impact on cardiac morphology as compared with the situation in which growth hormone deficiency sets in during adult life when the organ has already fully developed. Therefore, they represent good models to explore the genuine effect of chronic growth hormone excess or deficiency on the heart. In patients with growth hormone excess, left ventricular (LV) mass is significantly increased [810]. In some of them the increment fulfills the 
criteria for cardiac hypertrophy. On the other hand, GHD is associated with a marked decrease in cardiac mass [11, 12]. These changes represent a preferential growth effect on cardiac tissue, since cardiac mass in these studies was expressed as mass index, i.e. normalized by the body surface area. In addition to that, this is very likely a specific consequence of the altered growth hormone activity because when growth hormone excess is corrected by octreotide, LV mass decreases significantly after only three months [10]. Similarly, if a replacement therapy is performed in GHD patients, LV mass is restored [12]. So, the data support the idea that growth hormone is a regulator of cardiac growth in adult life.

The other important functional effect of growth hormone and IGF-I is on myocardial contractility. This is a difficult issue because contractility is the intrinsic ability of the cardiac fiber to develop tension independent of the loading conditions. The definition itself gives an idea of the difficulty to get reliable measures of contractility in vivo. Indeed, if one wants to explore contractility there is no way but to resort to in vitro models. In a recent study from the Beth Israel group in Boston, normal rats were treated with growth hormone for four weeks and then their cardiac function was assessed in the isolated organ [7]. The force of contraction was greater in the treated animals than in controls, independent of intracellular calcium concentrations. This suggests that growth hormone enhances contractility by a mechanism that does not involve calcium transients but rather the sensitivity of the contractile elements to calcium. In another investigation from the same group, the acute effect of IGF-I on contractility was tested. IGF-I was added to the perfusate of the isolated heart and within 1-2 min there was an increase of the developed force [14]. This finding provides unequivocal evidence for an effect of IGF-I on contractility that develops rapidly, is direct, and totally growth-independent.

Additional evidence for the cardiac regulatory role of growth hormone come from the Lewis dwarf rat $[15,16]$. In this model, contractilily is depressed. If these animals are treated with growth hormone replacement therapy, the developed force of their isolated heart is normalized. Again, this occurs without changes in calcium transients supporting the idea that growth hormone modifies the responsiveness to calcium and not its movement.

\section{Growth Hormone Indirect Cardiac Effects}

Growth hormone may also affect cardiac function through a wide spectrum of indirect mechanisms. Among them, the most consistently found is the decrease of peripheral vascular resistance (PVR). Growth hormone may also have an effect to raise preload through its sodium retaining action and its interference with the hormonal system that regulates water and electrolyte metabolism. Particularly important is the effect of growth hormone on skeletal muscle mass and performance. The improved physical activity together with the psychological well-being that the hormone brings may ultimately have a beneficial effect on cardiac performance through a conditioning mechanism.

PVR is reduced in acromegalics and markedly increased in patients with GHD [17]. From these data, we can draw a general picture on the hemodynamic effect of growth hormone. We can reasonably say that chronic growth hormone excess induces a hyperkinetic syndrome characterized by high cardiac output and reduced PVR, whereas in GHD there is a hypokinetic syndrome with low cardiac output and increased PVR.

In the presence of changes in PVR, one cannot easily know if they reflect a direct effect of a given factor on the resistance vessels or the change in PVR is simply the product of an indirect mechanism, for instance a baroreflex response to cardiac output. There is solid evidence to support a direct effect of growth hormone and IGF-I on PVR. Fryburg et al. directly infused IGF-I into the brachial artery in order to avoid as much as possible the intervention of systemic mechanisms [18, 19]. Forearm blood flow markedly rose. This response, in the presence of unchanged arterial blood pressure, indicates a fall in PVR. The mechanism by which IGF-I exerts this effect is through the synthesis of nitric oxide. In fact the co-infusion of an analog of arginine blocks the response [20-22]. These data provide an opportunity to expand on the role of NO in the mediation of some relevant clinical events related to GHD. This syndrome has been recently identified and, among the many manifestations, it is also characterized by a greater incidence of vascular disease (premature atherosclerosis, cerebrovascular accidents). In patients with GHD there is a significant intimamedia wall thickening of the large arteries and an 
increased incidence of atherosclerotic plaques [23]. The hypothesis may be formulated that NO plays a pivotal role in all the vascular changes associated with GHD. The evidence supporting this view comes from the observation that the urinary excretion of nitrates and cyclic GMP is reduced in patients with GHD and corrected with replacement therapy [24]. In parallel, PVR is normalized by growth hormone therapy. It must be stressed that NO, besides being the mediator of endotheliumdependent vasodilation, also inhibits smooth muscle cell proliferation, platelet aggregation, monocyte adhesion, and LDL oxidation. So, the removal of the NO brake on these processes may provide a clue to why in GHD there is an enhanced propensity to develop premature atherosclerosis.

\section{Growth Hormone and LV Architecture}

After reviewing the main direct and indirect effects of growth hormone on the cardiovascular system, it is important to specifically address the consequences of a given change in LV mass on LV geometry, as this will reverberate on cardiac function. The simplest way of analysing LV geometry is to measure the relative wall thickness. This is the ratio of ventricular wall thickness to the radius. The relative wall thickness was significantly increased in acromegaly [8-10], whereas in GHD it was significantly lower than in controls $[11,12]$. This was mainly a consequence of changes in wall thickness. LV dimension was marginally affected. Again these changes were corrected by the specific treatment. Therefore, growth hormone excess raises the relative wall thickness and induces an LV pattern that is reminiscent of concentric hypertrophy, whereas in GHD there is marked wall thinning and cardiac atrophy. The reason why these changes in the relative wall thickness are important and the way they are linked to ventricular function are explained by the Laplace's law. The relative wall thickness is a key determinant of LV wall stress. According to Laplace's law, wall stress is given by the ratio of LV pressure to the relative wall thickness. So, when this is high as it occurs in acromegaly we should expect a lower wall stress and the opposite is true in GHD. If we look at the wall stress data measured in a recent study, they confirm the expectations. Wall stress is decreased in acromegaly and increased in GHD [18]. Systolic wall stress is a measure of afterload and therefore it plays a preeminent role in cardiac performance, as anticipated by the force-velocity relation [25]. When the load imposed to the ventricle increases, the shortening velocity is impaired. Accordingly, in acromegaly wall stress is lower and cardiac output is increased, whereas in GHD the stress is higher and cardiac output is severely depressed. The increment in cardiac index in acromegaly was largely expected. Its marked decrease in GHD was quite striking. These patients complain of fatigue, they have a markedly reduced physical exercise and oxygen consumption that has been interpreted as a consequence of their reduced skeletal muscle mass and strength. We hypothesized that the impaired cardiac performance could be a contributing factor to their reduced physical activity. Thus, we measure cardiac performance in a group of patients with GHD at rest and during physical exercise. As compared with a control group of subjects, in GHD patients cardiac output was smaller both at rest and during physical exercise [13]. When these patients are treated with growth hormone replacement therapy, cardiac output response to physical exercise is restored to normal. In parallel, there is a marked improvement in physical exercise and quality of life.

\section{Growth Hormone in Heart Failure}

Considering the reviewed effects of growth hormone on the heart, and the pathophysiological mechanisms that characterize heart failure, the question arises as to whether any of these effects of growth hormone and IGF-I may be exploited in heart failure.

The primary event of heart failure is always a reduction of myocardial contractility, whether caused by ischemic damage or nonischemic cardiomyopathy. Consequently, there is an acute diastolic overloading and ventricular dilatation so that stroke volume is maintained by the preload reserve. This is a compensatory, acute mechanism. However, for reasons that are clearly apparent in Laplace equation, ventricular dilatation raises further diastolic stress and this continuous mechanical stimulus induces a growth response with series addition of new sarcomeres and ventricular dilatation. Now in some cases (small 
infarcts) the growth response normalizes wall stress and a new equilibrium is reached. If the loss of contractility is big, the extent of ventricular dilatation is out of proportion to the increase in mass. In other words, the growth response is inadequate and the relative wall thickness or the mass/volume decreases. From here there is only one exit and that is progressive deterioration of performance. This is the reason why one of the primary objectives in the treatment of heart failure is to break this vitious cycle. With angiotensin converting enzyme inhibitors this goal is reached by regression of cardiac growth and attenuation of ventricular dilatation [26]. The alternative approach to attenuate ventricular dilatation is to face up to this side of the circle and to potentiate the growth response so that to induce wall thickening, thus normalizing the relative wall thickness. Ultimately, hearts from different animal species have different ventricular size but they have a comparable relative wall thickness. So, if we induce a growth response in a dilated ventricle creating a proportional wall thickening in theory the negative impact of enlargement should be compensated for.

There is evidence that growth hormone is able to induce a growth response in the diseased myocardium. In a study using the postinfarction rat model of heart failure, growth hormone induced a significant increase of the left ventricular mass and, as expected, an increment in the relative wall thickness [27]. This was also followed by an improved systolic performance and an enhanced contractility, as measured in vitro in the isolated and perfused heart. There are only preliminary data regarding the effect of growth hormone on human dilated cardiomyopathy [28]. The data indicate that a 3 month treatment at the dose of 4 units every second day leads to a significant increment in the relative wall thickness. This is followed by a marked fall in the systolic wall stress and an increase in cardiac output particularly during physical exercise. So, the data suggest that growth hormone affects cardiac growth in humans and reshapes ventricular geometry in a hemodynamically favorable manner. The issue whether growth hormone may improve myocardial contractility in human heart failure has not been assessed adequately so far. However, a variety of indirect evidence suggests that this is possible. When growth hormone was given acutely to patients with mild to severe heart failure, there was a relevant increment in cardiac output [29, 30]. In these studies, it is difficult to explain the improvement in cardiac output simply as the consequence of the reduced peripheral vascardiac output. This may be due to an effect on contractility or to changes in the loading conditions. However, since the preload is unaffected and arterial blood pressure remains unchanged, one cannot exclude also enhanced contractility. This view would be supported by experiment in the perfused heart from rats with postinfarction heart failure. In this model, growth hormone improves the left ventricular developed pressure indicating an effect on contractility [27].

In conclusion, there is more than a reason to believe that the growth factor approach is rational. This does not mean that the approach is effective. There is a very long way to go before we understand whether growth hormone or related growth factors may indeed provide a new tool in the treatment of heart failure. We do not have yet an unequivocal proof of efficacy in human heart failure but only preliminary observations, case reports and very small studies. If the data of ongoing studies will support the efficacy of the hormone, then we have to look at the forms of heart failure that may benefit the most and we also must carefully look at possible adverse effects of long-term treatment, such as excessive growth of the cardiac tissue with interstitial remodeling and inevitable diastolic dysfunction. Finally, even if growth hormone proved beneficial and safe, the major problem remains as to whether it is able to affect disease progression. In general there is no relation between the short-term effect of a cardiovascular drug and the long-term outcome, i.e. survival and rate of hospitalization. The lesson from positive inotropic agents and phosphodiesterase inhibitors is quite frustating. These drugs exert great effects in the short term but they hasten disease progression.

There are two observations that suggest that growth hormone may be different from inotropic agents. First, the fact that growth hormone improves myocardial energetics and reduces oxygen consumption. This has been shown by our study as well as by previous studies in the early 90 's by Dr. Mercadier's group in Paris [31, 32]. The second point is that growth hormone seems to induce a deactivation of the neuro-humoral system. In our preliminary study, the myocardial spillover 
of norepinephrine and the circulating levels of aldosterone were decreased by growth hormone treatment [33]. To the extent that the neurohormonal system is not only a marker but causally related to cell death due to its cardiotoxicity, the fact that growth hormone deactivates the system provides an additional element of optimism.

\section{References}

1. Thorner MO, Vance ML, Horvath E, Kovacs $K$ (1992) The anterior pituitary. In: Wilson JD, Foster DW (eds) Williams Textbook of Endocrinology. $8^{\text {th }}$ ed, Philadelphia: WB Saunders Co, 221-310.

2. D'Ercole AJ, Stiles AD, Underwood LE (1984) Tissue concentrations of somatomedin C: further evidence for multiple sites of synthesis and paracrine or autocrine mechanisms of action. Proc Natl Acad Sci USA 81: 935-939.

3. Mathews LS, Enberg B, Norstedt G (1989) Regulation of rat growth hormone receptor gene expression. J Biol Chem 17: 9905-9910.

4. Ito $H$, Hiroe $M$, Hirata $Y$, Tsujino $M$, Adachi S, Shichiri M, Koike A, Nogami A, Marumo F (1993) Insulin-like growth factor-I induces hypertrophy with enhanced expression of muscle specific genes in cultured rat cardyomicytes. Circulation 87: 17151721.

5. Penney DG, Dunbar JC Jr, Baylerian MS (1985) Cardiomegaly and haemodynamics in rats with a transplantable growth hormone-secreting tumour. Cardiovasc Res 19: 270-277.

6. Cittadini A, Strömer H, Katz SE, Clark R, Moses AC, Morgan JP, Douglas PS (1996) Differential cardiac effects of growth hormone and IGF-I in the rat: a combined in vivo and in vitro evaluation. Circulation 93: 800-809.

7. Strömer H, Cittadini A, Douglas PS, Morgan JP (1996) Exogenously administered growth hormone and IGF-I alter intracellular calcium handling and enhance cardiac performance: in vitro evaluation in the isolated isovolumic buffer perfused rat heart. Circ Res 79: 227-236.

8. Fazio S, Cittadini A, Sabatini D, Merola B, Colao AM, Biondi B, Lombardi G, Saccà L (1993) Evidence for biventricular involvement in acromegaly: a Doppler echocardiographic study. Eur Heart $J$ 14: 26-33.

9. Fazio S, Cittadini A, Cuocolo A, Merola B, Sabatini D, Nicolai E, Colao AM, Biondi B, Lombardi G, Saccà L (1994) Impaired cardiac performance is a distinct feature of uncomplicated acromegaly. J Clin Endocrinol Metab 79: 441-446.

10. Merola B, Cittadini A, Colao A, Ferone D, Fazio S, Sabatini D, Biondi B, Saccà L, Lombardi G (1993)
Chronic treatment with octreotide improves cardiac abnormalities in patients with acromegaly. J Clin Endocrinol Metab 77: 790-793.

11. Merola B, Cittadini A, Colao A, Longobardi S, Fazio S, Sabatini D, Saccà L, Lombardi G (1993) Cardiac structural and functional abnormalities in adult patients with growth hormone deficiency. J Clin Endocrinol Metab 77: 1658-1661.

12. Amato G, Carella C, Fazio S, La Montagna G, Cittadini A, Sabatini D, Marciano-Mone C, Saccà L, Bellastella A (1993) Body composition, bone metabolism, heart structure and function in growth hormone deficient adult before and after growth hormone replacement therapy at low doses. J Clin Endocrinol Metab 77: 1671-1676.

13. Cittadini A, Cuocolo A, Merola B, Fazio S, Sabatini D, Nicolai E, Colao A, Longobardi S, Lombardi G, Saccà L (1994) Impaired cardiac performance in growth hormone deficient adults and its improvement after growth hormone replacement. Am J Physiol 267: E219-E225.

14. Cittadini A, Spindler $M$, Strömer $H$, Ishguro $Y$, Travers KE, Ingwall JS, Morgan JP (1997) Mechanisms of the IGF-I positive inotropic action. J Am Coll Cardiol 29: 404A (Abstract).

15. Cittadini A, Strömer H, Vatner DE, Grossman JD, Katz ES, Clark R, Morgan JP, Douglas PS (1997) Consequences of $\mathrm{GH}$ deficiency on cardiac structure, function, and $\beta$-adrenergic pathway: Studies in mutant dwarf rats. Endocrinology 138: 5161-5169.

16. Strömer H, Cittadini A Grossman JD, Morgan JP (1996) Normal cardiac function requires growth hormone. Circulation 94: I-421 (Abstract).

17. Fazio S, Cittadini A, Sabatini D, Merola B, Colao A, Biondi B, Longobardi S, Lombardi G, Saccà L (1997) Growth hormone and heart performance: a novel mechanism of cardiac wall stress regulation in humans. Eur Heart J 18: 340-347.

18. Fryburg DA, Gelfand RA, Barrett JB (1991) Growth hormone acutely stimulates forearm muscle protein synthesis in normal humans. Am J Physiol 260: E499E504.

19. Fryburg DA (1994) Insulin-like growth factor-I exerts growth hormone and insulin-like actions on human muscle protein. Am J Physiol 267: E331-E336.

20. Wu HY, Yue CL, Chyu KY, Hsueh WA, Chan TM (1994) Endothelial-dependent vascular effects of insulin-like factor $I$ in the perfused rat mesenteric artery and aortic ring. Diabetes 43: 1027-1032.

21. Haylor J, Singh I, El Nahas AM (1991) Nitric oxide inhibitor prevents vasodilatation by insulin-like growth factor I. Kidney Int 39: 333-335.

22. Tsukahara H, Gordienko DV, Tonshoff B, Gelato MC, Goligorsky MS (1994) Direct demostration of insulin-like factor-I-induced nitric oxide production by endothelial cells. Kidney Int 45: 598-604. 
23. Markussis V, Beshyah SA, Fisher C, Sharp P, Nicolaides AN, Johnston DG. Detection of premature atherosclerosis by high-resolution ultrasonography in symptom-free hypopituitary adults. Lancet 340: 1188-1192.

24. Böger RH, Skamira C, Bode-Boger SM, Brabant G, Mühlen A, Frölich JC (1996) Nitric oxide may mediate the hemodynamic effects of recombinant growth hormone in patients with acquired growth hormone deficiency. A double-blind, placebocontrolled study. J Clin Invest 98: 2706-2713.

25. Katz AM (1992) Myocardial contractility. In: Karz AM (ed) Physiology of the Heart. New York, Raven press, 303-318.

26. The SOLVD Investigators (1991) Effect of enalapril on survival in patients with reduced left ventricular ejection fraction and congestive heart failure. $N \mathrm{Engl}$ J Med 325: 293-302.

27. Cittadini A, Grossman JD, Napoli R, Katz SE, Strömer H, Smith RJ, Clark R, Morgan JP, Douglas PS (1997) Growth hormone attenuates early left ventricular remodeling and improves cardiac function in rats with large myocardial infarction. $J$ Am Coll Cardiol 29: 1109-1116.

28. Fazio S, Sabatini D, Capaldo B, Vigorito C, Giordano A, Guida R, Pardo F, Biondi B, Saccà L (1996) A preliminary study of growth hormone in the treatment of heart failure in patients with dilated cardiomyopathy. $N$ Eng J Med 334: 809-814.

29. Sütsch G, Donath M, Yan XW, Brunner HP, Follath F, Froesch ER, Kiowski W (1997) Beneficial hemodynamic effects of acute IGF-I in patients with chronic heart failure. J Am Coll Cardiol 29: 285A (Abstract).

30. Volterrani M, Desenzani P, Lorusso R, D'Aloia A, Manelli F, Giustina A (1997) Haemodynamic effects of intravenous growth hormone in congestive heart failure. Lancet 349: 1067-1068.

31. Timsit J, Riou B, Bertherat J, Wisnewsky C, Kato NS, Weisberg AS, Lubetzki J, Lecarpentier Y, Winegrad S, Mercadier JJ (1990) Effects of chronic growth hormone hypersecretion on intrinsic contractility, energetic, isomyosin pattern, and myosin adenosine triphosphatase activity of rat left ventricle. J Clin Invest 86: 507-515.

32. Mayoux E, Ventura-Clapier R, Timsit J, Hoffmann Bëhar-Choen C, Mercadier J (1993) Mechanical properties of rat cardiac skinned fibers are altered by chronic growth hormone hypersecretion. Circ Res 72: 57-64.

33. Capaldo B, Lembo G, Rendina V, Vigorito C, Guida R, Cuocolo A, Fazio S, Saccà L (1998) Sympathetic deactivation by growth hormone treatment in patients with dilated cardiomyopathy. Eur Heart J 19: 623-627. 